\title{
O papel da comunicação empresarial na implantação do programa de remuneração variável
}

\author{
The role of business communication in the implementation of the \\ variable remuneration program
}

\author{
Alex Francisco de Oliveira Barbosa ${ }^{[\mathrm{a}]}$, Mário Teixeira Reis Neto ${ }^{[\mathrm{b}]}$, \\ Luiz Cláudio Vieira de Oliveira ${ }^{[\mathrm{c}]}$
}

\footnotetext{
[a] Graduado em Administração de Empresas pelo Centro Universitário Newton Paiva, Mestrando em Administração da Universidade Fundação Mineira de Educação e Cultura (FUMEC), Belo Horizonte, MG - Brasil, e-mail: afo.barbosa@gmail.com ; alex.barbosa@ jucemg.mg.gov.br

[b] Doutor em Administração pela Universidade Federal de Minas Gerais (UFMG), professor Doutor do curso de Mestrado em Administração da Universidade Fundação Mineira de Educação e Cultura (FUMEC), Belo Horizonte, MG - Brasil, e-mail: mario. reis@prointernet.com.br

${ }^{[c]}$ Doutor em Literatura Comparada pela Universidade Federal de Minas Gerais, professor Doutor do Programa de Mestrado e Doutorado em Administração da Universidade Fundação Mineira de Educação e Cultura (FUMEC), Belo Horizonte, MG - Brasil, e-mail: violi@superig.com.br
}

\section{Resumo}

$\mathrm{Na}$ perspectiva de se manter eficientes, garantir a satisfação dos clientes e conquistar novos mercados, as organizações têm enfrentado, nos últimos tempos, uma série de desafios. A fim de garantir melhor desempenho organizacional atrelado às suas estratégias, essas organizações introduzem novas formas de remuneração como incentivo e garantia de aprimorar o desempenho de seus funcionários. Para o sucesso e a efetividade dos programas de remuneração, as organizações necessitam implantar uma comunicação empresarial eficaz e democrática. $\mathrm{O}$ artigo demonstra a necessidade de uma comunicação empresarial eficiente, que traduza, para os funcionários, os benefícios da adoção de um programa de remuneração variável, garantindo a aceitação e a participação deles e assegurando melhores resultados e novos patamares de desempenho.

Palavras-chave: Remuneração. Comunicação empresarial. Desempenho. Estratégia.

\section{Abstract}

Organizations have faced in recent times a number of challenges, in view of maintaining their efficiency, ensuring customer satisfaction and attracting new markets. In order to secure a better performance tied to their strategies, 
these organizations introduce new forms of remuneration as an incentive and to guarantee a better performance of its employees. To ensure the effectiveness of remuneration programs, organizations need to deploy an effective business communication and democratic. The article demonstrates the need for an efficient business communication to translate to employees the benefits of adopting a remuneration program generating acceptance and participation of them and ensuring better results and new levels of performance.

Keywords: Remuneration. Business communication. Performance. Strategy.

\section{Introdução}

As mudanças no ambiente externo, tais comoinovações tecnológicas, turbulências do sistema econômico financeiro, globalização, competitividade acirrada e exigência cada vez maior do consumidor, têm provocado transformações nas estruturas e no modelo de gestão das organizações. Como consequência, isso promove alterações nas atividades produtivas e no sistema de remuneração, que refletem diretamente no mercado de trabalho.

No novo cenário empresarial, não se espera mais que as pessoas apenas reproduzam atividades prescritas em seu cargo, mas que tenham maior e melhor desempenho vinculado aos objetivos da organização. E necessário que os funcionários extrapolem as funções e papéis descritos nos cargos e assumam atribuições e soluções de problemas não especificados. Para que os funcionários busquem novos desafios, a remuneração variável surge como um sistema que direciona o desempenho dos empregados segundo os objetivos e as estratégias da organização.

No modelo cultural e organizacional em que se utiliza a remuneração variável, é necessária uma comunicação capaz de divulgar os objetivos e a forma de funcionamento do sistema para todos os envolvidos. Dessa forma, um programa de remuneração e uma comunicação empresarial eficiente são questões que desafiam os gestores, na atualidade.

Assim, o objetivo deste artigo é analisar as relações entre os constructos remuneração variável e comunicação empresarial, no sentido de orientar os gestores de programas de remuneração variável a respeito do uso de uma comunicação empresarial que garanta o envolvimento de todos os funcionários na busca de maior eficácia no ambiente de negócios.

\section{A remuneração}

As organizações contemporâneas têm encontrado, nos últimos anos, um período de instabilidade, concorrência, globalização e evolução tecnológica que as coloca em posição de pró-atividade, eficácia e eficiência organizacional para se manterem no mercado. Para Reis Neto e Marques (2004), o aumento da eficácia organizacional é, cada vez mais, dependente da capacidade da organização de desenvolver e melhorar continuamente seu estilo organizacional e gerencial. Para as empresas de sucesso, isso ocorre por meio de práticas que se concentram nos funcionários, na remuneração, na orientação para a equipe e no compartilhamento de informações.

\section{A remuneração tradicional ou fixa}

A remuneração mais utilizada pelas empresas brasileiras, conhecida como tradicional ou fixa, tem como foco o cargo e não a pessoa. Isso inibe a criatividade, aumenta a burocracia, o conservadorismo e força os funcionários a se adaptarem a uma função pré-definida pela empresa. Copelli e Piccinini (2003) reforçam esse pensamento ao afirmarem que a remuneração tradicional tem como foco principal o valor interno e externo do cargo. As competências que a pessoa possui e aplica no trabalho não são consideradas. Assim, surge um sério problema, pois não há estímulo à qualificação, já que não há recompensa porisso. Wood Jr. e Picarelli Filho (2004) corroboraram esta visão, ao afirmarem que as práticas tradicionais de remuneração parecem não ser compatíveis com a nova realidade das organizações, uma vez que se tornaram inflexíveis, conservadoras e reconhecidas como entraves para os processos de mudanças organizacionais necessárias para tornar a organização mais dinâmica. 
Nas empresas mais competitivas, remunerar não é apenas pagar pela função ou pelo trabalho dos funcionários, mas extrair o máximo de uma folha de pagamento, no que diz respeito à relação custobenefício. Como parte desse posicionamento, as empresas vêm oferecendo a seus funcionários, nos últimos anos, benefícios e remuneração variável, juntamente com a remuneração tradicional, como forma de diferenciar-se no mercado de trabalho, ampliando atrativos para que eles possam permanecer na empresa ou para evitar a aceitação de um novo convite de trabalho.

\section{A remuneração variável}

O uso da remuneração variável é antigo. Entretanto, ela só passou a ser objeto de um número maior de publicações nas duas últimas décadas. Dellagnelo e Dellagnelo (1996) afirmaram que suas características favoráveis à boa prática da gestão eram uma alternativa coerente com a necessidade de flexibilização, que procurava aliar o comprometimento dos funcionários com os resultados da organização e vinculava a remuneração ao desempenho alcançado. Os autores afirmaram ainda que a remuneração variável era uma estratégia de remuneração que buscava maior comprometimento dos funcionários pelos resultados da organização, contrapondo-se à prática de remuneração fixa, em que o pagamento dos funcionários é vinculado ao cargo ocupado, independentemente do desempenho na organização.

Mais recentemente, Plothow (2006) explicou que a remuneração vem sofrendo mudanças, saindo de uma perspectiva burocrática, com ênfase em métodos e técnicas, para um campo mais amplo, em que as preocupações não mais residem na técnica, mas, sobretudo, no alinhamento do sistema aos objetivos e estratégias organizacionais. Andrade (2007) agregou que as organizações estão convivendo numa relação de intensa competitividade, e esse novo enfoque rompe com os modelos tradicionais, impondo uma nova remuneração e recompensa, conduzindo empregados e empregadores para uma visão mais integrada do negócio. Já Gondim (2009) corroborou com outros autores, ao afirmar que a remuneração variável, ou remuneração vinculada a resultados, é uma estratégia de remuneração que pretende o maior comprometimento dos funcionários na busca pelos resultados da organização. A remuneração variável não representa apenas um objetivo a ser atingido pelo funcionário: tende a tornar-se uma prática comum nas empresas que desejarem se destacar em um mercado competitivo, desde que elaborada a partir de critérios relevantes e bem dimensionados.

\section{Os tipos de remuneração variável}

No contexto brasileiro, os tipos mais adotados para a remuneração variável são o pagamento por produção, em que os funcionários recebem de acordo com a produção realizada; o bônus ou gratificação, utilizado nas grandes empresas multinacionais para remunerar os altos escalões, quando alcançam um resultado esperado; a comissão utilizada para remunerar os funcionários da área comercial, sob um percentual do volume de vendas; a participação nos resultados, em que são distribuídos ganhos financeiros, pelo alcance de metas pré-estabelecidas, como o aumento da produtividade ou a redução de custos; a participação nos lucros, em que é distribuída parte do lucro da empresa; e, finalmente, a participação acionária, como um incentivo mais em longo prazo, em que são distribuídas ações ou se faz a venda facilitada destas para os funcionários que ocupam cargos de direção em empresas de capital aberto. Importante ressaltar que fazem parte da remuneração variável os benefícios que os funcionários de empresas brasileiras vêm recebendo (REIS NETO; MARQUES, 2004).

No elenco de possibilidades de recompensar desempenhos, muitos confundem benefícios com remuneração. Benefícios não são variáveis, mas podem ser maiores ou menores, compulsórios (obrigatórios) ou espontâneos. Os benefícios obrigatórios são decorrentes de uma exigência legal. Entre eles estão o auxílio doença, o $13^{\circ}$ salário, o salário-família, as férias e o salário-maternidade. São benefícios espontâneos, dados por vontade própria da empresa, o vale-alimentação, a assistência médica, a assistência odontológica, o subsídio de estudo e outros.

A remuneração variável pode ser vista também como um conjunto de diferentes formas de pagamento, vinculando o cumprimento dos objetivos organizacionais à recompensa e transformando os funcionários em aliados da empresa. No entanto, Hipólito (2002) afirmou que as formas de recompensa devem ser capazes de reconhecer as 
diferenças individuais e os diversos ritmos que as pessoas têm em assumir responsabilidades, uma vez que esses aspectos acabam por traduzir diferentes contribuições para a organização.

\section{A visão estratégica da remuneração variável}

A remuneração variável deve trazer, para os trabalhadores, uma visão integrada do negócio, tornando-os comprometidos com o alcance das metas organizacionais. Por outro lado, a organização deve estar disposta a remunerar de acordo com o esforço de cada colaborador. Hipólito (2002) lançou mais um desafio aos gestores, ao mostrar que a organização deve encontrar modelos alternativos de gestão da remuneração, que considerem a crescente transformação do mundo e a nova dinâmica de atuação dos profissionais. Desconsiderar esse fenômeno e não reconhecer aquelas pessoas que vão além dos limites estabelecidos pelo cargo têm sido motivos de frustração e descontentamento para aqueles profissionais talentosos, que buscam assumir responsabilidades adicionais de forma sistemática. Apoiado nessa perspectiva, Gondim (2009) afirmou que, para o sistema de remuneração variável privilegiar o desempenho do funcionário e gerar motivação na equipe, é necessário que ele seja elaborado de forma que as pessoas confiem na organização e, assim, se comprometam com o processo. A autora entende que, qualquer que seja o tipo de remuneração variável, é preciso se ter em mente que as organizações devem alinhá-la às suas estratégias.

Numa outra vertente, Plothow (2006) levantou que, no sistema de remuneração, os elementos não financeiros, associados às necessidades humanas relacionadas ao desenvolvimento e aprendizado, tais como a perspectiva de carreira, ainda são subutilizadas ou não trabalhadas de maneira consciente pelas organizações. Atrelados a esse pensamento, Flannery et al. (1997), afirmaram que um sistema de remuneração deve ser dinâmico e estar integrado a outros processos voltados para pessoas, além de apoiar iniciativas de mudanças, ser claro e comunicado a todos os envolvidos. Andrade (2007) afirmou que, se esse programa for usado eficientemente, pode-se apressar a aceitação e o compromisso com a mudança. Nesse novo cenário, a implantação de um programa de remuneração variável significa uma mudança que rompe o paradigma de uma remuneração apoiada apenas em cargos e funções.

No desenvolvimento de um modelo de remuneração variável, os gestores devem procurar uma forma de garantir que todos os funcionários tenham conhecimento e consciência do programa. Como foi dito por Godói et al. (2004), nesse modelo, os funcionários devem ter a lógica de que, ao participarem do desempenho da empresa, estão também compartilhando seus eventuais riscos. Quando um programa de remuneração variável é implantado, ocorre uma profunda mudança cultural que deve ser acompanhada de confiança e crédito de todos os colaboradores. Apesar de a remuneração variável poder desempenhar um papel representativo na comunicação dos objetivos, valores, diretrizes e estratégias das instituições, ela não reforça por si só uma filosofia de atuação mais abrangente, que valoriza a parceria e o comprometimento dos funcionários com os negócios (FERDINANDO, 2006). Assim, a comunicação empresarial precisa trabalhar para disseminar essa nova cultura, estreitar a relação entre os diversos atores envolvidos no processo e gerar o esperado comprometimento de todos.

\section{A comunicação empresarial}

Para tratar do tema comunicação empresarial, é necessário entender o que é comunicação. Para Cardoso (2006), a ação comunicativa nada mais é do que a necessidade dos seres humanos de se comunicarem por meio de um diálogo argumentado. As argumentações são formas de comunicação quase extraordinárias e pressupõem muito mais que os relacionamentos humanos. Já Lopes (2006) entende que a comunicação é fundamental na gestão e nos procedimentos das organizações, auxiliando na condução de suas políticas, para que não se espalhem boatos, rumores e suposições. A comunicação permite o acompanhamento, a avaliação e o julgamento dos resultados. Por isso, deve envolver todos os atores que, direta ou indiretamente, participem do processo, a fim de que todos possam compartilhar do mesmo sentimento de missão e oferecer sua contribuição para o sucesso. O tema comunicação empresarial foi definido por Cahen (1990) como uma atividade sistêmica, estratégica e ligada ao alto escalão da empresa, que tem como 
objetivo principal criar, manter ou ainda mudar onde for negativa - a imagem da empresa diante de seus públicos prioritários. Ao detalhar o objetivo da comunicação empresarial, o mesmo autor enumera que ela deve, permanentemente: conscientizar a opinião pública em todos os segmentos e níveis da empresa; fortalecer a credibilidade; obter e ser fonte natural do noticiário favorável; obter reconhecimento positivo e boa vontade; abrir e manter canais de diálogo; motivar funcionários; e, ainda, favorecer a imagem pessoal da diretoria e gerência.

\section{A comunicação em ambientes de remuneração variável}

Antes mesmo de se pensar no alcance de bons resultados por meio de um programa de remuneração, o processo de desenvolvimento e consolidação da comunicação empresarial deve passar por profundas transformações no processo de gestão das empresas, na superação da burocracia e na busca por um ambiente democrático e dinâmico. Esse processo, entretanto, exige tempo, dedicação e comprometimento da diretoria da empresa, assim como o novo processo de remuneração. Segundo Sabbatini (2005), rompida esta etapa, a comunicação empresarial não só passa a contribuir, mas também a determinar e a influenciar a criação de novos processos e estruturas de gestão organizacional, visando à construção de um ambiente democrático, flexível e integrado, possibilitando que as ações de comunicação permeiem todos os processos de gestão.

Wood Jr. e Picarelli Filho (2004) explicaram que existem seis passos para a implantação do sistema de remuneração estratégica nas organizações. São eles: diagnóstico da empresa, definição de aonde a empresa pretende chegar e de um modelo conceitual de remuneração, construção e implantação do sistema de remuneração e garantia da evolução contínua do sistema. Os autores alertaram que, em paralelo, no passo de implantação do sistema de remuneração, há uma mudança organizacional em curso e que, para concluí-la com sucesso, é necessária uma comunicação eficaz, divulgando os objetivos e a forma de funcionamento do sistema de remuneração para toda a organização. Dessa forma, a comunicação deve garantir que todos os envolvidos, responsáveis e usuários do sistema de remuneração tomem conhecimento de seus princípios gerais, de sua implementação e mecanismos operacionais, garantindo transparência e clareza a todos os integrantes do processo.

Milkovich e Boudreau (1998) adicionam entendimentos nesse sentido, ao afirmarem que uma premissa básica na administração do programa de remuneração é a de que os funcionários precisam estar envolvidos nas escolhas do benefício que melhor os atenda, gerando satisfação e melhor desempenho. Para que essa escolha tenha sucesso, são necessárias informação e comunicação contínuas, garantindo melhor compreensão dos funcionários sobre o plano de remuneração e sua aceitação. Partindo desse pressuposto, Sabbatini (2005) explicou que, tanto estrategicamente como no seu papel de inteligência empresarial, a comunicação necessita ser sistêmica, integrada e flexível. Há obrigatoriedade da mudança dos fluxos e processos comunicacionais e das estruturas formais até então vigentes, para a criação de um ambiente aberto, passível de uma comunicação de duas vias. Assim, as políticas e ferramentas são implementadas na busca pela participação e para um relacionamento transparente entre os funcionários e, principalmente, entre os diversos departamentos da área de Comunicação.

Porém, não basta a formulação de políticas de comunicação integrada para que esse processo se concretize. É preciso que a democracia, na comunicação interna, e a participação dos funcionários passe a vigorar com naturalidade na empresa, ou seja, que faça parte da sua essência e do processo de gestão dela, como que intrinsecamente ligada ao corpo gerencial, ao restante dos funcionários, aos clientes. Ou seja, é o resultado da comunicação como espelho do processo de gestão. Tomando como base esses preceitos, Jensen, McMullen e Stark (2007) levantaram em seus estudos que, apesar de dois terços das pessoas pesquisadas gostarem da empresa em que trabalham e de $70 \%$ gostarem do que fazem, apenas $35 \%$ dos trabalhadores estão satisfeitos com seu salário. Esse é um problema que poderia ser trabalhado com uma boa comunicação. No mesmo texto, os autores expuseram que, pelo fato de a remuneração ser algo sensível e delicado para muitos, ter uma comunicação eficiente sobre salários, benefícios e incentivos é um dos principais desafios dos gestores. Os autores asseveram que é fundamental implantar um programa efetivo de comunicação estratégica, para auxiliar nos programas de remuneração. Recomenda-se que essa 
comunicação seja capaz de reduzir os temores, equalizar expectativas, minimizar os pontos negativos e as críticas do programa e de maximizar os prontos importantes para a empresa e os funcionários.

Em um primeiro momento, para que a comunicação seja eficaz, é necessária a participação efetiva da alta cúpula da organização, uma vez que os funcionários acreditam mais na alta direção que nos gestores intermediários ou no Departamento de Recursos Humanos. Em seguida, o novo programa de remuneração deve ser explicado exaustivamente, sem parecer uma propaganda. Para que isso ocorra, seus principais mensageiros devem ser os gestores envolvidos com os empregados. Esses gestores devem conhecer a fundo todo o programa: quanto melhor o entenderem, mais efetiva será a comunicação. Outra contribuição para os gestores foi dada por Jensen, McMullen e Stark (2007), ao explicarem que eles devem dar, a seus subordinados, a chance de realizarem questionamentos e de fazerem críticas ao programa de remuneração. Todas as perguntas devem ser respondidas e clareadas para aumentar a confiança que o subordinado tem em seu superior. Nesse cenário, ao setor de Recursos Humanos cabe prover assistência e ferramentas para que os gestores possam disseminar a comunicação do novo programa de remuneração. Os autores levantam ainda que algumas organizações utilizam certos funcionários, que possuem um perfil mais crítico, como seus aliados. Ao perceberem que uma pessoa, que é sempre crítica, resolve defender e falar bem de algo, os demais assumem que aquilo pode ser uma boa ideia.Apoiando esse entendimento, os estudos de Andrade (2007) mostraram que, durante a implantação do programa de remuneração variável, os obstáculos identificados pela empresa foram a falta de conhecimento dos empregados e as dificuldades de comunicação vivenciadas no início do processo de negociação. Para o autor, a empresa deve adotar uma comunicação empresarial adequada, visando a disseminar os pormenores do programa e a incentivar a contínua participação. A comunicação empresarial deve privilegiar mais o contato pessoal, trabalhos de grupo, reuniões diversas e, principalmente, atuação "ao vivo" dos principais executivos. Os processos tradicionais, como jornal interno, revista da empresa, quadro de avisos e circulares são menos eficazes, mas não devem ser desprezados. Andrade (2007) complementou que a comunicação empresarial e a credibilidade são aspectos importantes num programa de remuneração. Os colaboradores da organização precisam entender e confiar no plano o suficiente para acreditar que seus pagamentos aumentarão se sua performance melhorar. Para que isso aconteça, é necessário que exista um canal de comunicação aberto entre empresa e funcionários.

\section{A estratégia, a comunicação e a remuneração variável}

Sabbatini (2005) mostrou que, embora as empresas percebam e acreditem na importância e no papel da comunicação empresarial para sua manutenção e sobrevivência, há poucos sinais, na utilização de uma comunicação de forma estratégica e integrada, que perpassem toda a empresa como um reflexo do processo de gestão. Cardoso (2006) concordou com esse pensamento, ao demonstrar que é necessário compreender a estratégia organizacional, não mais como um exercício de previsão, conduzido por um grupo limitado de experts, mas como um processo de emergência estratégica envolvendo toda a coletividade, em cujo centro está a comunicação.

Para McMullen, Jensen, Stark (2007), a comunicação eficiente de um programa de remuneração é a chave para garantir que planejado será executado, uma vez que o programa de recompensas só será motivador se for entendido e aceito pelos funcionários. Nesse sentido, a comunicação deve mostrar o que a organização espera dos funcionários e como eles serão recompensados. Ela deve ser segmentada para diferentes grupos de funcionários, objetivando a transparência e a aceitação do novo programa de remuneração. Moraes e Correa (2008) ampliaram esta ideia ao explicarem a necessidade de os gerentes conhecerem, efetivamente, a importância estratégica da comunicação empresarial na obtenção de resultados de longo prazo. Para isso, eles necessitam desenvolver uma visão global e estratégica da organização, além de terem a habilidade de disseminá-la e consolidá-la nas equipes que gerenciam. Os mesmos autores afirmaram que o enfoque da administração tornou-se fundamental no desenvolvimento do processo comunicativo organizacional, em especial no que se refere à visão de conjunto e suas perspectivas de sobrevivência e expansão ao longo do tempo. Visualizar a comunicação empresarial nessa perspectiva possibilita desenvolver o processo 
comunicativo no âmbito gerencial, na ótica do negócio e da sua inserção no macroambiente.

Cardoso (2006) reforçou esse pensamento ao afirmar que não é mais possível conceber e executar planos, projetos e programas isolados de comunicação empresarial, mercadológica, de administração interna ou externa, pois uma estratégia comunicacional integra todos os setores da organização e envolve todos os seus participantes. Seguindo esse pensamento, é possível afirmar que o sucesso de um programa de remuneração variável passa pelas vertentes da estratégia, da comunicação empresarial eficiente e do crédito. Estratégia, pois o programa de remuneração deve estar vinculado às estratégias organizacionais, como forma de garantir melhores resultados no mercado em que atua. Comunicação empresarial eficiente, pois o funcionário irá participar da conquista dos objetivos da organização somente com informações claras, sem margem para dúvida e com contínuo incentivo. Finalmente, o crédito, uma vez que a organização deve ser transparente e garantir ao funcionário um acesso democrático no processo de criação do programa de remuneração variável. Deve-se disponibilizar as informações de desempenho da empresa em tempo hábil e, principalmente, deve-se privilegiar aqueles que realmente trabalharam para o alcance do que a organização almejou, com uma remuneração justa, que reflita o desempenho do funcionário.

\section{Considerações finais}

Os resultados deste estudo demonstram que existem duas grandes barreiras para os gestores nas organizações. A primeira é a implantação de um programa de remuneração variável, que seja aceito por todos e que traga melhores resultados para a empresa. A segunda é desenvolver uma comunicação empresarial eficiente, que traduza aos funcionários os benefícios de se adotar tal programa. A análise dos constructos remuneração variável e comunicação indicou, num primeiro momento, a obrigatoriedade da mudança dos fluxos da comunicação empresarial e das estruturas formais até então vigentes. A literatura revisada recomendou a criação de um ambiente aberto, passível de uma comunicação democrática, em que a participação dos funcionários vigore com naturalidade e em que estes façam parte do processo de gestão.

Num segundo momento, a implantação de um programa de remuneração variável deve garantir o comprometimento maior dos funcionários, na busca de melhores resultados para a organização. Conforme observado, esse resultado só será alcançado se houverem fontes para esclarecimento de dúvidas, transparência, clareza, e se os funcionários tiverem um real conhecimento de todo o programa de remuneração. Os funcionários somente comprarão a ideia e se envolverão no processo se entenderem todo o programa. Assim, a literatura aponta que uma remuneração variável só terá sucesso se a organização criá-la a partir de dois pilares: alinhamento às estratégias da organização e envolvimento de todos os funcionários.

Noque se refere ao primeiro pilar, os estudos mostraram que, para se obter o alinhamento estratégico, a organização deve indicar para os funcionários o que a organização pretende atingir com a implantação do novo programa de remuneração, ou seja, deixar claro para os funcionários o que se espera deles. O programa de remuneração variável deve trazer para os trabalhadores uma visão integrada do negócio, tornando-os comprometidos com o alcance das metas organizacionais; por outro lado, a organização deve estar disposta a remunerar de acordo com o esforço de cada funcionário. No desenvolvimento desse novo modelo, os gestores devem procurar uma forma de garantir que todos os funcionários tenham conhecimento e consciência do programa de remuneração variável, garantindo o envolvimento geral.

Quanto ao segundo pilar, foi apontado que o envolvimento de todos os funcionários da organização só pode seralcançado com uma comunicação empresarial democrática, clara e dinâmica, capaz de criar novos processos, continuamente. Esta forma transparente de se comunicar com os envolvidos é a chave para garantir que o que foi planejado será executado, uma vez que o novo programa de remuneração só será motivador se for entendido e aceito pelos funcionários.

Embora existam estudos que demonstram o forte vínculo da comunicação empresarial e o programa de remuneração variável, nota-se a necessidade de se entender como os gerentes podem utilizar melhor esses constructos de maneira prática e quais as melhores ferramentas para diagnosticar, definir, construir e implantar um programa de remuneração variável, atrelado a uma comunicação empresarial. A comunicação precisa fazer com que os funcionários entendam e confiem no plano o suficiente para acreditar que seus pagamentos aumentarão à medida que o desempenho melhorar e assegurar, por consequência, maior eficácia e sucesso no ambiente de negócios. 


\section{Referências}

ANDRADE, M. M. S. J. Programas de participação nos lucros e resultados - lei n. 10.101/2000 e comprometimento funcional em indústrias baianas de fertilizantes. 2007. 233 f. Dissertação (Mestrado em Administração) - Programa de Pós-Graduação em Administração da Universidade Federal do Ceará, Fortaleza, 2007.

CAHEN, R. Comunicação empresarial. São Paulo: Best Seller, 1990.

CARDOSO, O. de O. Comunicação organizacional: novos desafios teóricos. In: ENCONTRO NACIONAL DE PÓS-GRADUAÇÃO E PESQUISA EM ADMINISTRAÇÃO - EnANPAD, 30., 2006, Salvador. Anais... Rio de Janeiro: ANPAD, 2006. p. 6-16.

COPELLI, F. L.; PICCININI, V. C. Sistema de remuneração por habilidades para trabalhadores multifuncionais. REAd - Revista Eletrônica de Administração, Porto Alegre, v. 9, n. 2, p. 21-32, 2003.

DELLAGNELO, E. H. L.; DELLAGNELO, J. R. G. Modelos de eficácia subjacentes ao programa de remuneração variável. Revista de Negócios, v. 2, n. 1, p. 53-67, 1996.

FERDINANDO, L. C. dos S. O impacto da remuneração variável no desempenho dos funcionários das mesas de operações do setor bancário. Academos: Revista Eletrônica da Faculdade Interação Americana FIA, v. 2, n. 2, p. 32-45, 2006.

FLANNERY, T. P.; HOFRICHTER, D.; PLATTEN, P. E. Pessoas, desempenho e salários: as mudanças na forma de remuneração nas empresas. São Paulo: Futura, 1997.

GODÓI, C. K. et al. Remuneração acionária, sentimento de propriedade e motivação dos empregados. Revista de Administração Faces: Tecnologia de Gestão em Ação, v. 7, n. 2, p. 102-121, 2008.

GONDIM, D. C. M. Remuneração variável como impulsor na gestão por resultados. In: CONGRESSO CONSAD DE GESTÃO PÚBLICA, 2., 2009. Brasília. Anais... Brasília: SEPLAG - Secretaria de Planejamento e Gestão do Rio Grande do Sul, 2009. Painel 43: Remuneração variável e incentivos.

HIPÓLITO, J. A. M. Remuneração por competências: recompensando o desenvolvimento e a contribuição do profissional. RevistaFAE BUSINESS, n. 3, p. 28-31,2002.
JENSEN, D.; MCMULLEN, T.; STARK, M. The manager's guide to rewards. New York: AMACOM, 2007.

LOPES, G. A. A comunicação empresarial integrada a gestão participativa. estudo de caso: comlurb. 2006. 196 f. Tese (Doutorado em Tecnologias da Comunicação e Estéticas) - Escola de Comunicação da Universidade Federal do Rio de Janeiro, Rio de Janeiro, 2006.

MCMULLEN, T.; STARK, M.; JENSEN, D. The role managers can play in reward program effectiveness. Benefits \& Compensation Digest, v. 44, n. 5, p. 6-28, 2007.

MILKOVICH, G. T.; BOUDREAU,J. W. Administração de recursos humanos. São Paulo: Atlas, 1998. Cap. 13.

MORAES, M. G.; CORREA, M. L. Competência comunicativa dos líderes e os resultados da equipe. In: ENCONTRO NACIONAL DE PÓS-GRADUACÃO E PESQUISA EM ADMINISTRAÇÃO - EnANPAD, 32., 2008, Rio de Janeiro. Anais... Rio de Janeiro, ANPAD, 2008. p. 15.

PLOTHOW, C. B. de A. Fatores contingenciais à estratégia de remuneração da força de vendas. 2006. 249 f. Dissertação (Mestrado em Administração) Departamento de Administração da FEA - Faculdade de Economia, Administração e Contabilidade, Universidade de São Paulo, São Paulo, 2006.

REIS NETO, M. T.; MARQUES, A. L. A remuneração variável e sua contribuição para a melhoria da gestão. Revista Negócios, Blumenau, v. 9, n. 4, p. 5-18, 2004.

SABBATINI, J. N. Gestão e comunicação empresarial - uma leitura crítica. 2005. 104 f. Dissertação (Mestrado em Comunicação Social) - Programa de Pós-Graduação em Comunicação Social da UMESP Universidade Metodista de São Paulo, São Paulo, 2005.

WOOD Jr., T.; PICARELLI FILHO, V. Remuneração estratégica, a nova vantagem competitiva. 3 . ed. São Paulo: Atlas, 2004. Cap. 11, 13.

Recebido: 20/03/2010

Received: 03/20/2010

Aprovado: 03/05/2010

Approved: 05/03/2010 